ing of the arteries. In atheroma there is loss of elasticity and contractile power in the artery. After sudden muscular exertion the heart acts feebly till it has had time to recover itself, and the arteries are relaxed; in the case of mechanics whose occupation involves a free use of their upper limbs, as in planing, the arteries become stretehed, if not actually atheromatous, and their contractility becomes defective. In convalescents, again, in whom the murmur is often andible, it is frequent to find a relaxed condition of the arterial wall and an anæmic blood state. In all the conditions, then, in which the infra-clavicular murnur is commonly heard, conditions are present which may produce a want of relationship between the arterial calibre and the blood current. The other important condition in which the murmur is heard is in phthisis, but, though I believe -it to be here produced by or exactly in the same way as anæmia, I prefer to deal with it under a separate head.

I have already pointed out the influence of inspiration, of sex, and of the left side of the body upon the murmur below the clavicle. It will be seen that these are all explainable by the anatomical position of the subclavian artery, part of which is within and part outside the thorax. The effect of inspiration in increasing the intensity of the murmur, or in bringing it out when not spontaneously present, is explainable by the enlargement of the chest cavity produced by the inspiratory act. In inspiration the arteries in the thorax are exposed, like the lung, to the diminished pressure produced by the enlargement of the chest. In health this is resisted by the muscular contractility of the arteries, but even then a sensible diminution of blood-pressure is produced, ${ }^{6}$ and where there is flaccidity of the vessel wall and an insufficient quantity of blood in the arteries, they yield to the traction on their exterior and the calibre enlarges, thus producing the very conditions which give rise to a murmur-viz., defective relationship between the arterial calibre and the quantity of blood the vessel contains. In this way the subclavian and other arterial trunks within the thorax become dilated during inspiration, and vibrations occur in the blood current. The murmurs thus produced are often audible in the aorta, and sometines in its large branches within the thorax, though less often in the latter, as they are distant from the chest wall; in the part of the subclavian artery, just below the clavicle, the murmur is readily heard, and the full effect of the respiratory influence is made manifest. The relative frequency of the murmur below the clavicle on the left side of the body as compared with the right is accounted for by the mucl: greater lenoth of artery within the thorax on the left than on the right sile, in consequence of which the artery is much more exposed to the dilating force of inspiration. And possibly the greater frequency and intensity of the murmur on the left than on the right side may be also in part assignable to the fact pointed out by Dr. Latham, that "in many individuals there is a difference in intensity of the respiratory sound on the two sides, the respiratory sound being, with scarcely an exception, - distinctly louder over the left than the right lung." "The loudness and more common occurrence of the murmux in the female sex may be accounted for by their "superior costal "method of respiration, in which the great enlargement of the upper part of the chest in inspiration tends specially to expose the arteries in that region to the "negative pressure" to which I have alluded. Summing ap, then, what $I$ have said as regards the infra-clavicular murmur, it is one of the hæmic murmurs heard in various arteries produced by vibrations in the blood current arising fron defective relationship of the arterial calibre to the

6 "The heart and great bloodvessels are, like the lungs, placed in the air-tight thoracic cavity, and are subject, like the lungs, to the pumping action of the respiratory movements. Were the lungs entirely absent from the chest the whole force of the expansion of the thorax in inspiration would be directed to drawing blood from the extra-thoracic vessels towards the heart, and conversely the effect of the contraction of the thorax in expiration would be to drive the blood back again from the thorax in expiration would be to drive the blood back again from the heart towards the extra-thoracic vessels. The air does not pass into the pulmonary alveoi as freely as it would do into a pleural cavity through an opening in the thorace wall. Before the inspired air can enter a pulmonary alveolus, the walls of the alveolus have to be distended at the spense of the pressure uhich causes the inspired air to enter. .... During an inspiration, then, the pressure around the heart and great blood vessels becomes considerably less than that of the atmosphere outside the thorax. During an inspiration the diminution of pressure in the thorax around the aortic arch tends to draw the blood from the arteries sutside the thorax back to the arch of the aorta. At the same timeand this is the point to which we wish to call attention-the aortic arch tends to expand; in conserquence, the pressure of blood within it-i.e., the "rterial tension-tends to diminish." (Michael Foster Physiology, 3). 367.$)$ blood contained within it. It is heard best below the clavicle only because this is the first part of the artery which can be readily auscultated, and its rhythm and the various circumstances influencing or determining it are dependent on certain anatomical and physiological facts. In the other conditions than anæmia in which the murmur is sometimes to be heard, the same factors are present as in anæmia to account for it, and the same influences affect it.

(To be concluded.)

\section{A CASE OF}

\section{DOUBLE HYDRONEPHROSIS OF CONGENITAL} ORIGIN ; NECROPSY.

BY ALFRED G. BARRS, M.D., M.R.C.P.,

ASSISTANT PHYSICIAN TO THE GENERAL INFIRMARY, LEEDS ; LECTURER ON PHYSIOLOGY IN THE YORKSHIRE COLLEGE.

ON April 4th, 1888, I was asked by his medical attendant to see the patient whose illness is here described, on account of what was regarded, and with good reason, as the sequel will show, as an attack of acute Bright's disease. While examining the abdomen I was surprised to find a large mass occupying the right lumbar region; this, with the presence of blood in the urine, a specimen of which was shown to me, led me to make the provisional diagnosis of malignant disease of the kidney. I recommended his removal to the infirmary with a view to surgical interference, and on April 6th he was, by the courtesy of Dr. Eddison, admitted under my care. The following is the report of the case, written by Mr. H. A. Smith, house physician.

George $\mathrm{F} \longrightarrow$, aged thirty-one years; driller. Admitted on April 6th, 1888, complaining of pain in the abdomen and persistent vomiting. On a certain day, three years ago, the patient had been at work as usual, and felt quite well. In the evening of this day while watching some people playing at cricket, a ball came towards him, and he stooped to pick it up, when a sudden sickening pain took him in the loin, but on which side he cannot be certain. The pain lasted about half a minute. He leaned against a wall, felt very cold, and vonited; there was no blood in the vomit. He was unable to walk home alone, and was assisted thither by some friends. He went immediately to bed and again yomited, the romited matters consisting of stomach contents only. On the following day he had sufficiently recovered to be able to go to his work. He had not noticed any change in the urine passed during or after this attack, nor were the intestinal evacuations altered in any way. From this day three years ago until nine weeks before admission, he continued at his work ; but, nevertbeless, he did not feel so strong and well as he did before the day on which he had the attack of pain. He had no further attacks, nor was his attenticn called to his side by any pain or feeling of discomfort whatever. His appetite was good, the bowels acted regularly, and the urine was natural in appearance and quantity, but he had several attacks of vomiting without obvious cause. Then nine weeks ago he began again to vomit, and has vomited steadily every day since while taking food, or directly after, or some hours after, during the night, and before breakfast-in fact, at any and at all times. He had no fresh attack of pain, and he had not fallen or strained himself in any way. In a short time he began to experience pain in the abdomen which, however, he attributed to the constant vomiting. The pain was not at any time referred to the kidney, and there was no retraction of either testicle. He has lost weight rapidly. The bowels have been more or less confined during the last nine weeks. On April 1st, he vomited nearly a pint of blood, mixed with some milk which he had taken; this hæmatemesis was followed almost immediately by a profuse hæmorrhage from the nose. During this time he was attended by Mr. Hawkyard (with whom Dr. Barrs saw him), who had observed well-marked oedema of the face and other parts of the body, together with hamaturia, and had regarded the case as one of acute nephritis. He had had no previous illness of any serious nature, or bearing on his present condition in any way.

Present condition.-The patient is a well-built man, of pallid complexion, and somewhat wasted. The tongue is 
sore, dry, and brown in the centre. While lying in bed he does not experience any pain. He vomits constantly, and with a striking suddenness, scarcely having time to reach the basin from his locker. He is passing only a small quantity of urine, of sp. gr. 1012, acid in reaction, and albuminous. The skin is dry and harsh. There is no jaundice. The liver dulness begins at the sixth rib in the nipple line, and does not extend beyond the costal margin. The organ cannot be felt. The spleen cannot be felt. There is no odema. Abdomen not markedly tender on palpation. No swelling noted in epigastric region. Lineæ transversæ of recti muscles well marked, and muscles somewhat rigid. Opposite to and above the umbilicus on the right side of the abdomen the rectus muscle is seen to be more prominent than on the left side, and the right loin is found to be distinctly more full than the left. On palpation, a hard rounded mass can be felt coming up to within an inch of the umbilicus, and extending upwards, to be lost beneath the costal margin, the costal margin being, however, prominent and distinct. Below, the mass disappears deeply, close to the iliac crest. The mass can be readily moved by the hand in the right lumbar region, and this region is seen, when the patient is sitting up, to be distinctly prominent. The tumour has a solid feel to the touch, is dull on percussion at all points of its surface, and no fluid wave or thrill can be detected in it, nor is any bruit audible on auscultation over it. Examination of the left side of the abdomen gives no indication of a tumour or any abnormality. The superficial abdominal veins are not enlarged. There are no pressure pains, and the testes are not retracted. The vomited matters are acid in reaction, of yellow colour, and this morning contain several small flakes of blood.

A pril 8th. - The vomiting has continued almost incessantly since admission. No change in the condition of the abdonen. Urine: eightounces passed in twenty-four hours ; sp. gr. 1012; acid ; albuminous; no deposit.

9th.--No change. Urine: six ounces passed in twenty. four hours; sp. gr. 1010; acid; albuminous.

10th. - The patient continues to vomit, and is evidently losing ground rapidly. All feeding by the mouth was ordered to be stopped and nutrient suppositories to be administered every four hours. At 1.15 P.M., after consultation, it was decided to explore the tumour. Mr. McGill introduced a fine aspirator needle into the most prominent point of the mass, and drew off eighteen ounces and a half of fluid resembling urine. This fluid was of specitic gravity 1009, was faintly acid, and contained albumen, chloride of sodium, and urea $(1 \cdot 3$ per cent.). At 10 P.M. the patient was rather restless, and shivered slightly. Has not vomited since aspiration.

12th.--Has not retained the nutrient suppositories. Bowels acting frequently; fæeces fluid, and of a light yellow colour; no traces of blood. During last night there was much mental confusion; he was noisy, and constantly trying to get out of bed. One-third of a grain of nitrate of pilocarpine was given yesterday morning, after which he sweated freely and seemed better. Has passed only eleven ounces of urine during the last twenty-four hours; sp. gr. 1013, highly albuminous, and containing blood and granular débris. Shortly after a hot-air bath he became rapidly comatose, and died at 11.55 P.M. The temperature was subnormal throughont the time he was under observation.

Necropsy.-Urinary organs: On opening the abdomen and displacing the small intestines, the tumour in the right lumbar region was readily exposed, with the second part of the duodenum tightly stretched across the upper and inner part of its anterior surface, and was seen at once to consist of an enormously dilated kidney. The whole of the urinary apparatus down to the membranous urethra, together with the renal vessels and corresponding portions of the aorta and vena cava, were removed and carefully dissected. The appearance of the parts is well shown in the annexed woodcut, which has been taken from a photograph of the preparation. Both kidneys were converted into cysts, to the surface of which the wasted and altered kidney tissue proper was applied. The right kidney measured in its greatest length $7 \frac{1}{2}$ in. and in its greatest breadth $5 \frac{1}{2}$ in., and may be said to have completely filled the posterior part of the right abdomen, reaching downwards to the brim of the pelvis and inwards to the middle line. It contained about twenty ounces of a urinous-lonking fluid stained with blood. The walls of the cyst were flaccid, and composed of a dense white glistening membrane, almost of the consistency of the dura matier, and having very much the appearance of that structure. Towards the attachment of the ureter the cyst consisted of a single chamber, while in the direction of the kidney proper it assumed a more or less loculated arrangement indicating the remains of the infundibula. The kidney proper, much elongated and expanded, was applied to the upper and outer border of the cyst, in the manner shown in the drawing. The surface was of a dead ivory-white colour, and more or less lobulated, corresponding to the dilated calyces within. On section, the pyramids were found to be almost entirely destroyed, the remaining cortex measured about a quarter of an inch in thickness, was almost of cartilaginous hardness, and had. lost all resemblance to normal renal tissue. The inner surface of the cyst was entirely free from any trace of inflammatory action, or renal concretion. The left kidney had undergone precisely the same change, and though the cyst into which it had been converted was much smaller

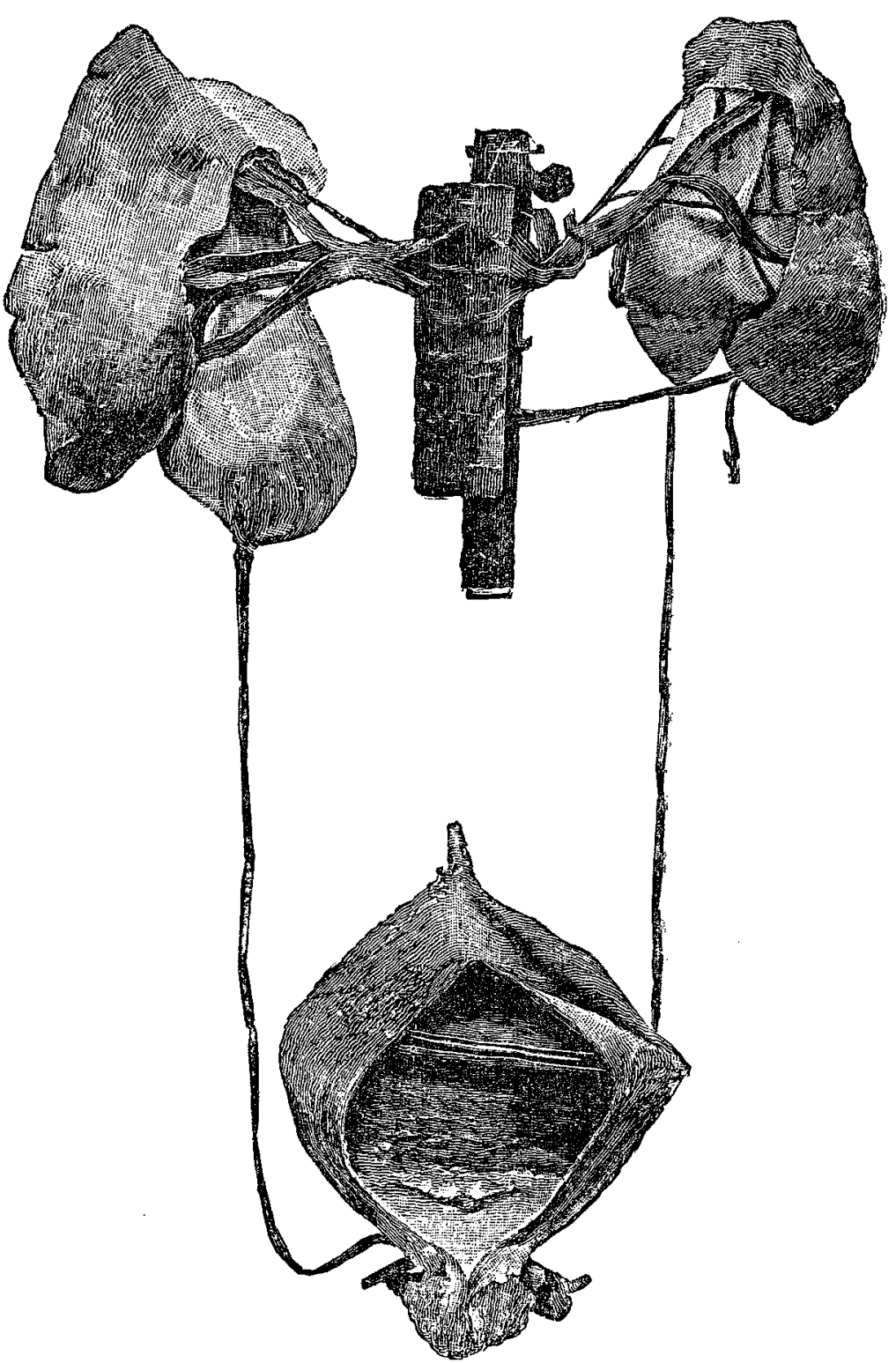

than that on the right side, the kidney proper was represented only by the thinnest possible shell of renal substance, the criginal nature of which could only be known from its shape and relation to the cyst wall. The renal vessels were tightly stretched upon the dilated pelves, and though the arteries were unusual in their number and distribution, they were not arranged in such a manner as to suggest that they had been the cause of the obstruction to the outflow of the urine. The ureters by contrast with the kidneys appeared to be unusually small, and were certainly not dilated. They were of equal calibre throughout, and were normal in their course to the bladder and free from any external pressure or constriction. A stylet passed easily from the bladder upwards into the kidney, but was not passed from above downwards, owing to the fact that the uretal openinginto the pelvis could not be found. On withdrawing the stylet, which had been passed before the cyst was opened, fluid could readily be expressed from the right kidney into the bladder. The attachment of the ureter 
was in such a position that the enormously dilated pelvis was "tapped" at about the middle point of its inner aspect, so that in the natural condition of the parts the ureter may be said to have been inserted very much after the manner shown in the drawing at p. 546 of Sir William Roberts's work. $^{1}$ (In the woodcut it will be seen that the parts have fallen out of their natural positions in the body, and have become in many ways altered from shrinking of the cysts.)

Remarks.-As to the cause of the extreme dilatation of both kidneys, I am unable to suggest any hypothesis but that which refers it to a congenital defect in the method of insertion of the ureters into the renal pelves. It will at once be seen from the drawing that there is no trace of any cause of obstruction below the pelvis of the kidney. The ureters were of normal calibre, if not reduced in size, and there was no vestige of obstruction in the ureteral orifices, in the bladder, or in the urethra; so that I am inclined, without much hesitation, to class the case with two described by Sir William Roberts ${ }^{2}$ as illustrating " in a striking manner how a congenital malformation, which at first only offered a slight obstruction to the course of urine, comes step by step to constitute a greater obstruction, and at length produces fatal results"; in fact, with a few alterations in details, such as the absence of intestinal obstruction and the non-occurrence while he was under observation of any large escape of urine, the case is almost identical with Sir William Roberts's case"T. S—, aged twenty." A striking feature, clinically, was the occurrence of all the graver manifestations of Bright's disease - viz., œdema, hromaturia, and finally death by coma; and I am inclined to think, from a careful consideration of this case, that the appearance of such manifestations ought to suggest very strongly the bilateral nature of the lesion in those instances where the physical examination of the abdomen reveals an enlargement of one kidney only; if this be so, the importance of the observations, from a surgical point of view, cannot well be overestimated, and I am strongly inclined to think that in any case of hydronephrosis, apparently unilateral, where general odema or any indications of the uræmic state has been observed, surgical interference, of a radical nature at any rate, is inadmissible. It wonld be interesting to speculate how an obstructive condition of the renal outlet existing from birth comes to be compatible with life during thirty-one years. The most probable explanation, it seems to me, is that this and probably all the recorded cases of bilateral hydronephrosis due to congenital defect in the arrangement of the ureters belong to the intermittent form of the disease, though, as in the above case, the periodic emptying of the tumour may have never been observed. The flaccid condition of the left sac, noticed at the post-mortem examination of my case, would seem to suggest this view, for though the destruction of the kidney on the left side was much farther advanced than on the right, the left sac could not be felt during life, nor was there any history of a tumour in the left abdomen. The vomiting, which was most persistent and distressing throughout the case, was due undoubtedly to the mechanical stretching of the duodenum upon the surface of the tumour. How extreme this tension must have been is indicated by the fact that on more than one occasion considerable hæmorrhage had taken place into the stomach.

Leeds.

\section{THE HISTORY AND USE OF ANESTHETICS IN MIDWIFERY.}

\section{By FRED. W. ALLWRIGHT, M.D., L.R.C.S.I.}

IN the present article I propose discussing a subject which must necessarily be of interest to the medical profession, and one about which there has been, and is, a variety of diverse opinion, both as to the substances used and their method of application. I wish, in the first place, to enter into their history as far as space will permit; then to discuss the individual merits of each; and, finally, to suggest the best methods of application.

The history of surgical anæsthesia is now well known. Throughout all ages attempts have been made to relieve the nain of surgical operations. Then came suggestions under

1 Urinary and Renal Diseases, fourth edition, 1885.2 Op. cit., p. 544. the light of advancing chemistry, followed by the efforts of some and the achievements of others, until, in the year 1846, a state of unconsciousness to pain was produced so effectually, that from that date artificial anæesthesia entered upon a scientific existence. There had been also in obstetric practice the same effect and the same desirability of relieving suffering, which has always been throughout all ages one of the most striking features of humanity. Childbirth had been observed to go on with regularity and without suffering under certain pathological conditions of the nervous system. In a case reported by Olliver, the spinal cord was compressed from the first to the fourth dorsal vertebra. In another case observed by Hasse, there had been a fracture of the fourth cervical vertebra. There was one recorded by Daneux, in which delivery took place during the unconsciousness of intoxication from alcohol.

The honour of first having induced unconsciousness during delivery by the administration of ether is due to Simpson of Edinburgh. He used this anæsthetic in 1847 in three cases, all of which were succesaful. Professor Simpson laid the subject before the Obstetrical Society of Edinburgh, and presented the following facts before it, derived from his experience: (1) That the inhalation of ether produced a more or less perfect immunity from the pain and suffering of labour; (2) that it did not diminish the strength or regularity of the contraction of the uterus, but that it tended to increase it, especially when combined with ergot; (3) that the contraction of the uterus after delivery seemed perfect and healthy; and (4) its exhibition did not seem injurious to the child. The step from surgical to obstetric anæsthesia was but a short one, it is true; but it was over a chasm of unknown depth. Trial alone could prove whether uterine contractions continued, and thus labour progressed during the unconsciousness of ether. The fact, therefore, of uterine contraction continuing during etherisation having been verified, obstetrical anæsthesia was established.

The first period in the history of the above covers the discovery of the facts that uterine contractions would continue while pain was abolished, and that no deleterious influence was exerted by ether, with the general acceptance of the method for preternatural labours and obstetrical operations. This period was cut short, as far as ether was concerned, by the introduction of a new anæsthetic agent. Simpson was again the path-breaker. From the first time he saw ether inhaled he felt convinced that there were other substances capable of producing the same effects in a more efficient manner. Up to this time-a period of about fifteen years-chloroform was known only as a chemical curiosity. This substance was suggested to him by Waldie, a chemist. Various experiments were made with the new substance, the result of which was that chloroform was found superior to ether, inasmuch as it possessed a more agreeable odour, the quantity required to produce anæsthesia was much less than in the case of ether, drops taking the place of drachms, and secured the freedom of the air-passages from irritation, as caused by the latter; the action of chloroform was found also to be much more rapid than that of ether. The introduction of chloroform marks the second stage in the development of anæsthesia in obstetrics, and had it not been that some deaths had taken place from its use in surgical operations it would doubtless have held the field alone. It is needless here to enter into the details of the controversy that followed for some time concerning the advantages and disadvantages of the two substances, nor will space permit; it is sufficient to say that chloroform and ether had many friends and many enemies, and amongst them the highest authorities. Not only was the contest carried on with respect to the two substances, but also upon the subject of anosthesia as applied to natural labour. On one side was a firm conviction of right and a noble impulse to benefit humanity; on the other, caution, a wholesome fear of interference with a natural process, and a dread of resorting to such powerful remedies unless life were endangered.

Obstetrical A nosthesia. - General anæsthetics are administered in labour in two classes of cases-(1) in obstetrical operations and in painful mancuvres; and (2) in normal labour, to mitigate or annul pain. 'The first class of cases differs in no respect from that of surgery in essential points. More important in obstetrics because two lives are at stake, deep ancesthesia is the same in one as in the other, and but a few points require consideration. In the second class, however, the process is a special one, and demands careful study. The object here is to mitigate or annul pain 